\title{
Exploration on Urban Planning Based on the Wisdom City
}

\author{
Hui Ma ${ }^{1, a}$ \\ ${ }^{1}$ Beijing Weibang Yatai Planning Co., Ltd. Dongcheng Dist, Beijing, 100007 \\ ${ }^{\mathrm{a} e m a i l,}$
}

Keywords: Wisdom City; Urban Planning; Innovation and Development

\begin{abstract}
With the development of urban informatization, intelligent city has become a new concept of urban planning on a global scale. The planning and planning of the intelligent city requires the corresponding changes in the traditional urban planning, which has had an important impact on the urban planning. This paper analyzes the basic idea and concrete work flow of the wisdom city, analyzes its influence on the urban planning, discusses how to break the limitation of the traditional urban planning from the angle of the intelligent city, and implements the innovation of the urban planning in practice, so that the city can be sustainable development, for the residents to create a better life.
\end{abstract}

\section{Introduction}

Smart city planning is based on the status quo of the city, urban economic and social development planning, is an important task affecting urban development. It aims to solve the problems of urban environment, management, transportation and other infrastructure in the process of urban development, and then promote the development of urban economy, improve the quality of the environment, facilitate urban traffic and improve the city management to meet the growing needs of people.

\section{The Basic Concept of Intelligent City}

In simple terms, the smart city is the social capital, including traditional transportation, modern communications and other infrastructure and natural resources intelligent. The basic idea is to focus on sustainable development and improve people's living standards and the most significant feature is the integration of modern information technology, the connotation of urban innovation, technological innovation, management innovation and organizational management innovation interaction as a whole. However, the concept of intelligent city is not simply urban construction plus information, but the application of innovation in modern society, its core is through the information technology to achieve human and economic, socio-economic and natural resources, the balanced development of its final Inspection standards is the city's comprehensive strength has been improved. Specific can be detailed from the following aspects:

Urban Public Management Form. Urban public management focuses on urban management, infrastructure, emergency systems and government services: government services can be integrated into modern information technology, comprehensive management and integration of daily business, to be transformed into intelligent government services; infrastructure can be installed Sensing the probe, in the digital network based on the creation of a set of GPS positioning and data processing functions of the management service system, law enforcement management more simple and convenient; intelligent environmental protection, you can use intelligent technology to build a command platform, real-time dynamic monitoring environment changes and to Analysis, early warning of pollution in order to facilitate the early detection of hidden dangers and to eliminate.

The Way of Urban Social Resources. The use of urban resources mainly has the power system and the use of water resources. If the concept of intelligent city to carry out urban planning, the need to combine the actual situation of the city's development, scientifically predict the future trend of the industrial park and road traffic projects such as scientific layout. Wisdom Power, through the combination of information flow and power flow, in the power transmission to collect data, the use 
of the module to optimize the depth of mining power data analysis, and to provide information to the decision-making departments; wisdom of water resources, through the collection of water quality and traffic, after the background server analysis the results directly with the various departments to share, to achieve the rational use of water resources and management protection.

Urban Industrial Structure. The smart industry includes emerging information technologies such as Internet of Things, Mobile Broadband, Supercomputing and Cloud Computing, as well as new industries such as high-end manufacturing, smart finance and intelligent media, which are derived from traditional industries. Such as the wisdom of logistics, through the construction of a commodity supply chain system to improve the loading of transport vehicles, optimize the transport path, improve storage space, can effectively improve the commodity circulation rate and greatly reduce logistics costs. Wisdom business, through the construction of a unified office system, can effectively integrate the company's data information, more effective allocation of resources and people have more time to carry out innovative projects, greatly reducing resource consumption.

\section{The Work Processes of the Wisdom City}

Smart city planning needs to combine the specific circumstances of the city, the use of scientific ideas to plan out the program can effectively support the development of the city need to focus on comprehensive planning and top-level architecture design. In addition to planning the city information industry and communications infrastructure, we also need to plan the construction and operation of intelligent city mechanism, system, laws and regulations and network ethics.

Smart city planning system is very large, need a clear planning process, specifically for the following five steps.

Concept Planning. Fully understand the wisdom of the city's philosophy, the global construction of the situation and the application of ICT technology, the target city of intelligent planning and construction to determine the construction of the regional scope, the required functions and preliminary overall objectives, proposed program and planning mission.

Collect Basic Information. According to the concept planning plan to compile the basic data plan, usually from two aspects: First, the collection of existing basic information, including urban and surrounding maps, urban planning, government work reports and information infrastructure status; Interviews are conducted primarily for key stakeholders.

Analysis the Basic Information. After collecting the above basic information, we can analyze the research from the perspective of the overall goal and function analysis of the wisdom city, and decide how to use it.

Function Design. Start functional design must first clear the overall orientation of the wisdom of the city fully understands the needs of the various functions. Functional design content is divided into urban operation and management, information and communication infrastructure, e-government, industrial development support and public services.

System Architecture Design. Smart city can be designed from the following aspects of the system architecture: operational architecture design, security architecture design and technical architecture design. One of the technical architecture designs is an important part of the wisdom of urban planning, but also the basis of urban operation.

\section{The Impact of the Wisdom City on Urban Planning}

Affect the Planning System. Smart city is a new development concept and management model for urban development, which is the new direction of urbanization in the future. The traditional urban planning system must make the corresponding changes, usually reflected in two aspects: First, the basic direction of urban governance with the wisdom of the city's concept of change, change the work of urban planning; the second is to promote the new city and other intellectual industry development, such as the development of things, can greatly promote the wisdom of the city's progress.

Impact Planning Units. Urban planning, the preparation of the unit is very important, but also 
constitute an important part of the urban planning system, the wisdom of the city after the impact of urban planning system will inevitably affect the preparation of units. The compiling unit needs to change the business type and traffic volume and expand it.

Influence Planner. Although the wisdom of the city just emerging, but the development potential is huge, planners need to learn new theories to better adapt to the development of the times, improve their comprehensive ability to meet the promotion of intelligent city to lay the foundation. In addition to continue to expand the optimization of personnel can be regularly training, training process to fully improve the professional skills of the planners, and strengthen its overall quality, to master the essence of the wisdom of the city concept, the ability to complete the wisdom of urban planning knowledge integration.

Affect the Planning of Industrial Structure. The establishment of the smart city requires the relevant infrastructure, which will inevitably promote the development of its infrastructure manufacturers, thus affecting the industrial structure of urban planning. Embodied in the city traffic command, wisdom, electricity and so on. So the industrial structure also need to adjust accordingly, to strengthen the intelligent application, otherwise it may make the market chaos affect the wisdom of the development of the city.

\section{The Practice Innovation of Urban Planning}

Traditional urban planning has great limitations, and there are many shortcomings, which can be summed up as follows: blueprint planning is static, lack of dynamic practice debugging; too much emphasis on technical applications and neglect of integrated planning; planning closed, mainly dependent In the elite and lack of public communication. Specifically, it can be analyzed from the following aspects:

Failure to adequately meet the needs of the public, usually urban planning is limited to the distribution of land, with little regard for human, geographical, economic, and social trends. And the lack of intelligent planning tools, urban planners are difficult to break the limitations of this demand forecast, only subjective estimates, resulting in the needs of the public cannot be met.

Private interests and public interests are not balanced, social justice is the fundamental urban planning, the law needs to express the provisions of public land and private land between the proportions of planning must be strictly observed. However, the reality is often due to the lack of intelligent measurement tools and government blind pursuit of economic growth, public facilities, supporting demand is often overlooked.

Public supply cannot meet the needs of the city, since the global outbreak of financial crisis in 2008 led to economic recession, the national central government and local governments is bound to significantly shrink the budget cannot provide effective infrastructure for public funds protection, resulting in public supply cannot meet the needs of urban residents.

The system is imperfect, "not within the term", "has nothing to do with me", need to further enhance the status and role of urban planning departments also need a good coordination and communication.

In order to solve the above problems, this section gives some suggestions on the idea, basis, key and method of urban planning from the perspective of wisdom city.

Planning Ideas. Correct control of the interrelationship between systems and the predictability of planning. In view of the current problems of urban planning, there is an urgent need for a set of intelligent systems to serve the public as the core, analyze the data to make decision support, balance the public interest and private interests to meet the needs of the people. In order to facilitate policymakers and planners to better manage the dynamics of the city, IBM has developed a system dynamics model for intelligent cities that can analyze the effects of real-world simulation planning decisions in urban systems to be able to test medium and long term planning.

Planning Basis. Prepare guidance documents such as the introduction of laws and regulations. In order to meet the city needs of the wisdom of the city, we must revise and improve the relevant laws and regulations supporting the system for the preparation and implementation of urban planning to provide legal protection. More and more cities in the country put forward the wisdom of the process, 
around the city planning are facing a huge challenge, we must adjust the demand. Therefore, from the national level to develop the wisdom of urban planning policies and regulations have a lead and the need for.

Planning Priorities. The wisdom of the city's planning philosophy into quantitative indicators and spatial layout of the form. The urban effect and change produced by the development of the wisdom city will eventually be reflected in the spatial layout of the city and become the quantitative index of urban planning, and the spatial layout of the city will change. The concrete implementation step is to develop a set of scientific and reasonable scientific index system according to the goal of the planning concept of the wisdom city, then transform the quantitative index into the suitable urban spatial layout form, and finally integrate the multiple target into the basic unit of urban construction.

\section{Conclusion}

The current wisdom of the city has become a development trend, is a new concept of urban construction, and the development of urban planning is the wisdom of the city construction of the top priority. The wisdom of the city in many ways affect the modern city planning, in the future urban construction should always control the development of smart city requirements, innovation in practice, optimize the direction of urban development, and ultimately create a scientific and complete intelligent city planning network to lay a good foundation for regional development.

\section{References}

[1] XI Guang-liang, Zheng Feng. Intelligent Urban Spatial Organization and Planning Based on Sustainable Development Goals [J]. Journal of Urban Development Research, 2014, 5 (11): 102-109

[2] Cheng Dazhang, Shen Wow. Planning planning process of intelligent city planning[J]. Intelligent building and city letter, 2013 (07): 101-106.

[3] Cao Fang. Intelligent city concept in urban planning application[J]. Building materials development orientation, 2016 (02): 162-163.

[4] Zhang Chun, Li Lei, Xia Haishan. City Planning from the perspective of the wisdom of the city's review and reflection[J]. International Urban Planning, 2016 (01)

[5] Qin Xiang. Intelligent city development on the impact of urban planning[J]. Technology and Innovation, 2016 (20): 41 